\title{
Mengenal Indonesia Melalui Netflix Original Movie
}

\author{
Desy Budi Utami \\ Departemen Mass Communication, STIKOM LSPR \\ Sudirman Park Campus Jl. K.H. Mas Mansyur Kav.35 Jakarta Pusat 10220, Indonesia \\ desy.budi@gmail.com \\ Masuk tanggal : 02-06-2018, revisi tanggal :06-12-2018, diterima untuk diterbitkan tanggal : 12-01-2019
}

\begin{abstract}
Culture is one of the approached on shaping up the nation image. Movies, for example, successfully create an image of "super power" country; exotic land; not to mention the most enchanting holiday destination in the world. Convergence era bring forth the "on demand" culture, it is a situation where the citizen freely consumed any kind of cultural "menu". As like Netflix, most Indonesian favorable online streaming media nowadays, from California. Compared to other online streaming media, Netflix made a good collaboration with global film maker to served original movie and series as one of their eminence. By doing so, Netflix also encourage its audiences to get to know more the "global culture" through the eye of its original movies. In Indonesia, Netflix officially release its premier original movies collaborating with Indonesian cinemas, titled "The Night Comes for Us". This research is aim to point out how the trailer of "The Night Comes for us" displaying and reflecting Indonesian image with Jean Baudrillard concept of simulation. Roland Barthes semiotic analysis's concept is also being use in this research as a bridge to understand first and second phase of Baudrillard's concept. The research concluded that the film trailer did not representing any kind of reality, but only a certain designed of Indonesian image. The displayed image that seen on the trailer is a commodity to persuade audience to watch the movie. Image simulation displayed on the trailer is created with the motives to "win" a certain target segmentation of audience.
\end{abstract}

Keywords : creative industry ethics, cultural studies, netflix, simulation-simulacra.

\begin{abstract}
Abstrak
Citra sebuah bangsa dapat dibentuk dengan berbagai cara, salah satunya dengan pendekatan kebudayaan. Lewat film misalnya, sebuah negara dapat dicitrakan sebagai bangsa "adi kuasa", negeri yang eksotis, hingga destinasi liburan paling menyenangkan di dunia. Era konvergensi media lahirkan budaya "on demand", dimana masyarakat bisa bebas menentukan sajian budaya apa saja yang ingin mereka konsumsi. Seperti misalnya, Netflix, layanan media streaming dari California yang mulai populer dinikmati publik Indonesia. Netflix menyajikan Netflix original movie and series, yang diproduksi oleh Netflix dan bekerjasama dengan sineas global sebagai keunggulan dibandingkan layanan streaming lainnya. Netflix mengajak penontonnya untuk mengenal kebudayaan global dengan film-film orginalnya. Di Indonesia, Netflix secara resmi dan perdana ini merilis Netflix original movie dengan judul "The Night Comes for Us". Penelitian ini bertujuan untuk menunjukkan bagaimana cuplikan film "The Night Comes for Us" menampilan dan merefleksikan citra Indonesia dengan berpijak pada model pencitraan Jean Baudrillard yang dimulai dari tahapan representasi, ideologi, simulasi dan simulakra. Analisa semiotika Roland Barthes digunakan dalam penelitian ini sebagai jembatan untuk memahami fase pertama dan kedua pencitraan Baudrillard. Temuan yang didapatkan
\end{abstract}


menjelaskan bahwa citra Indonesia yang di tampilan dalam cuplikan objek penelitian tidak mewakili realitas apapun, melainkan sebuah bentukan belaka. Citra yang ditampilkan tak lain adalah sebuah komoditas yang digunakan untuk merayu penonton. Simulasi pencitraan didasari dengan motivasi untuk "memenangkan" segmentasi pasar tertentu.

Kata Kunci: etika industri kreatif, cultural studies, Netflix, simulasi-simulakra.

\section{Pendahuluan}

Sering kali seseorang maupun institusi dikenal karena sebuah "citra" yang melekat kepadanya. Misalnya, sebuah merek shampoo dengan sengaja menggunakan seorang penyanyi kelahiran Indonesia namun berkewarganegaan Perancis untuk membangun citra perempuan anggun "ala" Indonesia. Begitu juga dengan film-film "superhero" besutan Hollywood yang seolah ingin menegaskan citra Amerika Serikat sebagai negara adidaya.

Budaya memiliki peran penting dalam mengonstruksikan citra sebuah negara (Anholt, 2007). Produk kebudayaan seperti media massa, film, musik, dan fesyen, seturut berjalannya waktu memiliki kontribusi besar dalam menyebarkan berbagai macam citra negara. Produk kebudayaan yang telah beralih menjadi industri adalah industri yang fungsi utamanya memproduksi dan mendistribusikan seni, hiburan, dan informasi. Sebagai bagian dari produk industri budaya, industri film adalah industri yang juga berperan dalam mempopulerkan citra sebuah bangsa. Citra suatu bangsa dibentuk oleh proses komunikasi yang sangat kompleks yang melibatkan beragam sumber informasi, salah satunya dengan media massa (Kunczik, 1997). Citra tersebut pun dapat berkembang sejalan dengan fase pencitraan yang dimulai dari representasi hingga hiperealitas (Baudrillard, 1983). Tulisan ini akan fokus pada cuplikan film Netflix original movies pertama yang dibuat oleh sineas Indonesia, berjudul The Night Comes for Us.

Tulisan ini berupaya untuk menunjukkan bagaimana cuplikan film The Night Comes for Us, sebagai salah satu film karya anak bangsa yang berkesempatan untuk "bertarung" dengan film-film besutan sineas global lainnya dalam "jagad" Netflix menampilkan dan merefleksikan citra Indonesia. Dalam rangka mencapai tujuan tersebut, penulis berpijak pada model pencitraan Jean Baudrillard yang dimulai dari tahapan representasi, ideologi, simulasi dan simulakra.

Film, bagian dari media massa dan sebagai produk kebudayaan telah menciptakan makna pesan yang tidak mewakili realitas. Bentuk konstruksi budaya media massa seperti ini disebut Baudrillard sebagai simulacra. "Simulacrum tidak pernah merupakan sesuatu yang menyembunyikan kebenaran ia adalah kebenaran yang menyembunyikan bahwa tidak ada apa-apa. Simulacrum adalah benar" (Ecclesiaste). Simulasi bisa dikatakan sebagai proses representasi sebuah objek. Seorang simulator akan berusaha untuk membuat objek yang ingin di representasikannya terlihat nyata, seperti acuannya (Baudrillard, 1983). Seperti halnya cara kerja para sineas dalam membuat film. Representasi kehidupan yang 
sebenarnya ditiru dalam setting film, pilihan busana, dialek hingga akting sehingga seolah-olah terlihat nyata seperti acuannya.

Namun sebenarnya tidak ada lagi cermin "ada" dan penampakan yang benar-benar nyata, melainkan hanya miniaturisasi genetik yang disebut sebagai dimensi simulasi (Baudrilard, 1983). Realitas buatan diproduksi menjadi unit- unit tiruan dari realitas yang ada. Realitas buatan ini dapat direproduksi berulangulang, tidak harus rasional sebab pada akhirnya tidak ada lagi yang menjadi patokan ideal (Baudrillard, 1983). Simulasi kemudian tak lebih dari sekedar operasional. Simulasi tidak lagi dibalut dengan imajiner, ia tidak lagi real, tapi menjadi hyperreal. Pada tahap inilah sineas berhasil "menyihir" para penontonnya. Membuat penonton terbayang-bayang adegan kekerasan setelah menonton film, misalnya.

Representasi dimulai dengan sebuah prinsip, yaitu tanda dan yang real itu setara. Sedangkan simulasi mulai dari utopia tentang prinsip kesetaraan. Simulasi dimulai dari negasi radikal tanda sebagai nilai, dari tanda sebagai pembalikan dan matinya setiap referensi (Baudrillard, 1983). Agar lebih singkat dan jelas Baudrillard menggambarkan pencitraan menjadi 4 fase. Fase pertama ialah representasi, yaitu citra menjadi cermin suatu realitas. Pada fase citra yang kedua, citra menyembunyikan dan memberi gambar yang salah akan realitas. Pada fase ini pula citra telah masuk pada tataran ideologi. Di fase ketiga citra menyembunyikan absen atau ketiadaan realitas. Pada fase terakhir, citra tidak ada hubungan sama sekali dengan realitas apa pun (Baudrillard, 1983).

Hilangnya makna secara langsung terkait dengan tindakan, melarutkan informasi, media, dan media massa. Inilah yang disebut dengan implosi (Baudrillard, 1994). Seperti yang terjadi dalam film, sering kali kepentingan sineas untuk menghadirkan kesan tertentu menutupi makna dari cerita maupun pesan moral yang ingin disajikan. Seolah citra adalah segala-galanya. Seperti dikutip dari laman korporasinya (Netflix, 2018), Netflix merupakan sebuah penyedia layanan streaming bagi pelanggan yang menawarkan banyak variasi film, mulai dari serial TV, dokumenter, hingga film-film terkemuka. Semua layanan dapat diakses dimanapun pelanggan berada dengan menggunakan beragam gawai, seperti misalnya smart TV, smart phone dan tablet. Pelanggan dapat mengakses semua layanan tanpa terganggu dengan iklan. Lain dengan berlangganan cable tv yang cenderung mendaur tontonan "itu-itu saja", setiap bulannya pelanggan Netflix disuguhi oleh "suguhan orisinal" berupa serial TV, film maupun show baru yang berasal dari berbagai belahan dunia.

Saat tulisan ini dibuat, Netflix telah berhasil mendapatkan 130 juta pelanggan dari 190 negara yang menikmati layanan Netflix yang diterjemahkan dalam bahasa lokal maupun diproduksi secara lokal dengan menggandeng sineassineas lokal. Pelanggan sebagai penonton bisa menonton, memberhentikan sejenak tontonannya hingga melanjutkan kembali tontonan mereka tanpa jeda iklan sekalipun. Seperti dilansir dari laman koroporasi resminya (Netflix, 2018), Netflix menyarankan para pelanggan dan calon pelanggan potensial untuk semakin banyak menonton dengan mempromosikan kampanye binge watching (ketagihan menonton), agar Netflix semakin baik dan "terlatih" untuk merekomendasikan serial TV maupun jenis-jenis film kegemaran para 
pelanggannya. Selayaknya aplikasi berbasis teknologi lainnya, Netflix pun menggunakan sistem alogaritma terstruktur yang diprogram untuk mengikuti "selera" para pelanggan (Tyron, 2015).

Layanan Netflix hadir secara resmi dalam bahasa Indonesia sejak 18 Oktober 2018. Dikutip dari siaran pers peluncurannya, Jessica Lee, selaku Vice President Corporate Communication Asia menyatakan, Netflix ingin lebih mudah diakses dan relevan bagi konsumen mereka, dalam hal ini masyarakat Indonesia. Tidak berhenti sampai disitu, upaya Netflix untuk menjadi relevan dan "dekat" dengan masyarakat Indonesia diwujudkan dalam film orisinal garapan sineas Indonesia. Adalah Timo Tjahjanto (Timobros) berlaku sebagai sutradara film The Night Comes for Us, film Netflix original pertama dari Indonesia. Timobros menggandeng aktor Indonesia yang juga karyanya telah dikenal di kancah Hollywood, antara lain Joe Taslim dan Iko Uwais sebagai pemeran utama dan tokoh sentral dalam film berdurasi 60 menit ini. Sebelum dirilis secara global di Netflix pada 19 Oktober 2018, film ini berhasil mendapatkan tanggapan positif pada Fantastic Festival 2018 di Amerika Serikat. Film yang menyoroti konflik anggota organisasi kriminal. Dikisahkan Ito (Joe Taslim), seorang anggota six seas salah satu Triad yang paling disegani di Asia kembali "pulang" ke keluarga kriminalnya di Jakarta. Sebagai seoang pembunuh berdarah dingin dan perwakilan organisasi kriminalnya di Asia Tenggara, Ito melakukan apa pun yang diinginkan oleh para "bos"-nya.

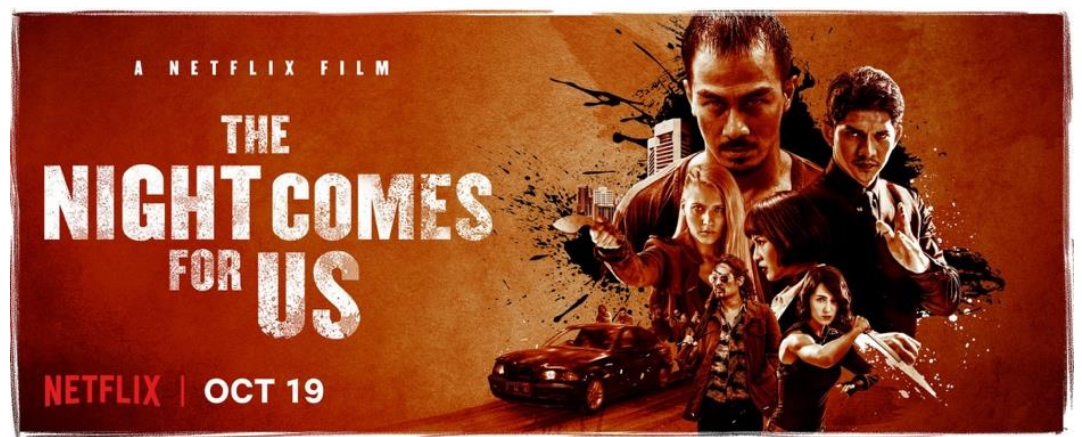

Gambar 1: Film poster The Night Comes for Us

Mulai dari merampas hak orang lain, hingga menentukan hidup atau mati orang-orang yang tidak bersalah. Suatu ketika setelah menyelesaikan "tugas" pembantaian yang dilakukannya terhadap penduduk desa, nurani Ito tergugah ketika melihat seorang anak perempuan kecil yang "tersisa" dari pembantaiannya. Ito pun menyelamatkan anak kecil itu dan melawan teman-temannya sendiri. Organisasi Triad tidak tinggal diam atas sikap anomali Ito, dan memutuskan untuk "memburu" Ito. Untuk mencapai misi itu, Triad-pun mengirim Arian (Iko Uwais) sahabat lama Ito untuk "mengembalikan" Ito menuju jalan yang gelap. Film ini menggunakan Bahasa Indonesia dan sesekali berisikan dialog berbahasa Mandarin. Dari awal hingga akhir, film ini memuat adegan kekerasan yang disajikan dalam bentuk visual maupun percakapan. 


\section{Metode Penelitian}

Penelitian ini menggunakan metode kualitatif dengan pendekatan interpretatif. Penelitian ini bersifat idiographic, yaitu menempatkan temuan dalam konteks waktu dan historis yang spesifik. Sehingga kebenaran yang ada bukanlah satu-satunya kebenaran dalam konteks historis tertentu dan waktu tertentu. Penelitian kualitatif menggunakan asumsi filosofis, strategi, pengumpulan data, analisa dan interpretasi yang berbeda. Jenis penelitian ini mengandalkan teks dan image sebagai data (Cresswell, 2009). Data yang dikumpulkan menggunakan metode purposive sampling, berupa gambar dan teks yang terdapat dalam cuplikan film. Pada penelitian ini penulis menggunakan metode analisa Rolland Barthes untuk mencari mitos dan ideologi yang terdapat dalam cuplikan film The Nights Comes for Us.

Mitos ialah "rumah" dari ideologi (Barthes, 1972). Mitos ialah bagaimana kebudayaan menjelaskan atau memahami beberapa aspek tentang realitas atau gejala alam. Mitos merupakan produk kelas sosial yang sudah mendominasi. Penelitian ini tidak membuktikan keabsahan suatu teori, melainkan ingin menunjukkan fenomena yang tengah terjadi di masyarakat melalui kacamata sebuah konsep. Dalam hal ini konsep yang digunakan ialah model pencitraan Jean Baurdillard, untuk menunjukkan proses pembentukkan simulasi dari cuplikan film untuk menggiring penonton. Seperti dikatakan Cresswell (2009) salah satu ciri khas penelitian dengan pendekatan kualitatif adalah adanya theoretical lens, yaitu penulis menggunakan sebuah "kacamata" untuk melihat sebuah fenomena yang tengah berlangsung.

Penggunaan semiotika Roland Barthes dalam penelitian ini sebagai pisau analisa dan jembatan menuju simulasi dan simulakra Jean Baudrillard. Yulianti, F.D., Bajari, A., Mulyana, S (2017), tujuan utama penggunaan semiotika Roland Barthes untuk menganalisis media berdasarkan asumsi bahwa media dikomunikasikan melalui seperangkat tanda. Barthes (Allen, 2003) memiliki tiga tahapan membongkar tanda pada media yang dianalisis yaitu; tahap denotasi, tahap konotasi dan mitos atau ideologi sebagai tahapan akhir yang merefleksikan tanda tersebut melalui sudut pandang kultur tertentu. Fase representasi dan mitos adalah fase pertama dan kedua menuju tahapan simulasi Jean Baudrillard.

Pada penelitian ini, objek penelitian utama adalah cuplikan atau trailer film The Night Comes for Us. Fokus penelitian adalah beberapa adegan yang memuat bahasa, pengambilan gambar maupun fesyen yang ditampilkan dalam cuplikan film.

\section{Hasil Penemuan Dan Diskusi}

Setelah menonton keseluruhan film The Night Comes for Us, penulis kemudian memilih adegan dalam film yang sekiranya mengandung penanda yang cukup kuat dan mewakili penelitian. Adegan-adegan yang dipilih terutama berpusat pada cuplikan atau trailer film, kemudian dikombinasikan dengan scene yang terdapat pada film secara keseluruhan. Dalam film ini, penulis memaknai 
citra seorang kriminal dihidupkan dengan fase-fase simulasi dengan berbagai aspek, yaitu bahasa, pakaian dan bahasa tubuh yang digunakan.

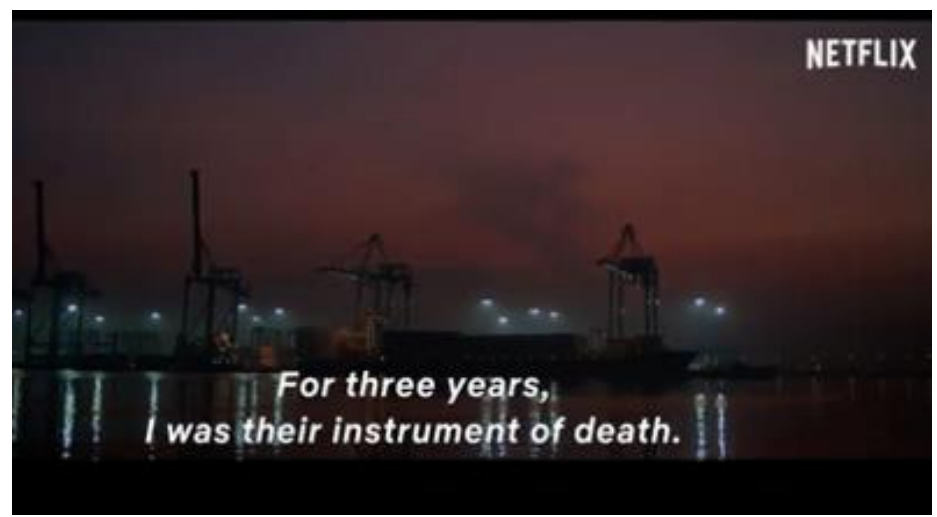

Gambar 2: Scene pertama dalam cuplikan The Night Comes for Us

Dalam film The Night Comes for Us, simulasi diciptakan dari realitas pada saat setting film beralih ke Jakarta. Dalam cuplikan film terlihat situasi pelabuhan di Ibu Kota Indonesia. Secara denotasi pelabuhan memiliki makna tempat persinggahan dan perdagangan. Pelabuhan adalah salah satu ujung tombak perekonomian sebuah negara dan menjadi tempat penting sebagai penanda akulturasi budaya, yang melahirkan budaya pesisir. Secara konotasi makna yang tersurat adalah tempat "gelap", kumuh, dan dekat dengan kriminalitas. Mitos yang terbentuk dalam scene ini adalah pelabuhan sarang kriminal. Setelah mengetahui mitos yang terdapat dalam scene ini, peneliti kemudian mengaitkan pelabuhan sebagai fase simulasi sebagai upaya untuk menghadirkan citra kriminal di Ibu Kota.

Melalui fase simulasi, seolah ingin menyampaikan kesan Ibu kota Indonesia, tak dipungkiri seperti layaknya metropolitan lain di belahan dunia lainnya tidak bebas dari kriminalitas. "Pelabuhan" sengaja diselipkan dalam scene untuk mensimulasikan daerah yang dianggap dekat dengan sarang kriminalitas dan etnis minoritas Indonesia, yaitu Tionghoa, yang mengusai peta perdagangan di utara Jakarta. Untuk lebih menguatkan, pada scene awal trailer juga memasukkan unsur-unsur Tionghoa, yaitu lampion, tulisan berbahasa Mandarin pada sebuah dekorasi, hingga scene yang menunjukkan beberapa orang tengah bersembahyang dengan membakar hio. Meskipun etnis Tionghoa minoritas di Indonesia, namun, jalinan kriminalitas para tokoh utama digambarkan bukan sekadar minoritas. Mereka adalah orang-orang yang bekerja untuk jaringan kriminal kelas dunia.

Pada cuplikan yang mayoritas berfokus pada pengambilan gambar cepat dan voice over, scene pertama menampilkan istilah "mesin pembunuh". Istilah "mesin pembunuh memiliki makna denotasi sebagai kumpulan alat-alat yang apabila disalahgunakan pemakaiannya dapat menyebabkan kematian, sepeti misalnya pisau dan senjata api. Secara konotatif "mesin pembunuh" memiliki makna sebagai orang yang berlaku sebagai alat-alat yang membahayakan. Sehingga timbulkan mitos para pemain utama merupakan orang-orang yang tak 
tertandingi, tak ada satupun yang dapat mengalahkan kehebatan mereka sebagai kriminal tingkat tinggi.

Proses simulasi tak berhenti sampai di sana. Aspek penggunaan bahasa, film The Night Comes for Us banyak menggunakan bahasa Indonesia yang digunakan percakapan sehari-hari hingga makian kasar sebagai ungkapan ekspresi dan drama antar tokohnya. Hal ini tentu sengaja digunakan untuk memperkuat proses simulasi dalam film. Selain "mesin pembunuh" yang ditampilkan dalam trailer, salah satu sapaan sering ditujukan kepada tokoh sentral dalam film ini.

Ito, tokoh sentral yang menjadi buronan dilabeli dengan sapaan "anjing" bagi kelompok Triad. Kata "anjing" memiliki makna denotasi yaitu sebagai hewan berkaki empat, yang memiliki taring tajam dan meskipun beberapa jenis terlihat menggemaskan, mereka tetap berbahaya. Makna konotasi dari kata "anjing" sering kali didapat dari sifat binatang anjing, yang terkenal sebagai binatang peliharaan yang setia. Sehingga, mitos yang terbentuk melampaui makna denotasinya, yaitu merupakan representasi dari seseorang yang setia terhadap organisasinya, namun juga berbahaya seperti hewan yang dapat menyerang sewaktu-waktu.

Kedua istilah "mesin pembunuh" dan "anjing" yang kerap diucapkan dalam dialog seolah saling "mengisi" untuk membentuk simulasi percakapan seorang kriminal yang sering kali diasumsikan melulu bersikap kasar. Hal ini seolah ingin menegaskan, kehidupan keras yang dialami para kriminal menjadikan mereka terbiasa menjadi kasar, baik dalam tindakan maupun dalam berbahasa. Jelas penggunaan kata tersebut tidak merepresentasikan citra Indonesia yang dibentuk sebagai bangsa yang ramah dan menghargai sopan santun ketimuran. Sehingga, tahapan simulasi pun bergeser menjadi simulakra yang menuju para hiprealitas.

Selain bahasa Indonesia sehari-hari dan cenderung kasar, film ini juga menampilkan tokoh-tokoh yang fasih berbahasa Inggris dan juga Mandarin. Penulis sebagai penonton, memaknai penggunaan bahasa ini dapat dibaca sebagai upaya sineas untuk menciptakan distinction, sebuah konsep pertarungan kelas yang diusung oleh Piere Bourdieu (1984). Dalam konsep distinction Bourdieu, strategi untuk menunjukkan kelas dapat tercipta dengan memanfaatkan kapitalkapital yang dimiliki oleh individu. Kapital tersebut antara lain ialah kapital sosial, kapital ekonomi, kapital budaya dan kapital simbolis.

Film ini menampilkan tokoh-tokoh utama yang lihai bersahutan dalam tiga bahasa, yaitu Indonesia, Inggris, dan Mandarin. Dikaitkan dengan konteks bisnis di Indonesia saat ini, penguasaan ketiga bahasa ini dianggap sebagai "resep" untuk bertarung di dunia bisnis maupun bursa kerja. Terbukti dari pengenalan ketiga bahasa ini secara bersamaan pada banyak sekolah di tingkat pendidikan anak usia dini. Keanggotaan tokoh-tokoh sentral sebagai Triad "Six Seas" mengharuskan mereka fasih dalam dua bahasa dunia, Inggris dan Indonesia. Bahasa, dalam konsep kapital Bourdieu termasuk dalam kapital budaya. Sedangkan, kapital ekonomi tidak digambarkan sebagai orang-orang dengan status ekonomi mapan, namun, secara kapital sosial para tokoh digambarkan saling kenal dengan orang-orang berpengaruh. 
Sebuah penanda penting dalam kaitannya dengan proses simulasi Baudrillard ialah melalui kapital simbolis, yaitu "kriminal yang go international", sineas secara terang-terangan ingin menunjukkan kepada penonton, mereka sedang menyaksikan tontonan kriminal yang berbeda kelas dari film kriminal Indonesia kebanyakan. Tokoh-tokoh yang lihai menggunakan "trilingual" sebagai strategi distinction untuk menciptakan ciri khas film ini dibandingan dengan sineas lokal lainnya. Selain menegaskan para tokoh yang terlibat adalah world class criminal, penggunaan bahasa ini juga seolah ingin merefleksikan film ini sebagai karya kelas dunia, juga merefleksikan citra para penontonnya (pelanggan Netflix), yang tentu saja, para early adaptors, yang terbiasa menggunakan bahasa asing sebagai distinction dalam kesehariannya.

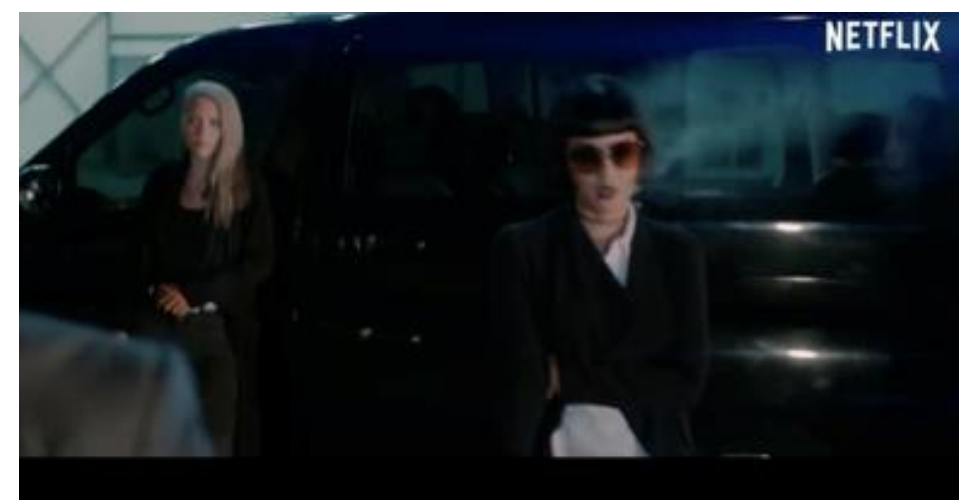

Gambar 3: Dominan Warna Gelap Sebagai Identitas Kriminal

Menurut Baudrillard, simulasi yang efektif tidak akan membuat seseorang percaya pada sebuah entitas palsu tetapi berarti realitas asli sudah tergantikan. Pada aspek kedua atau pakaian, film The Night Comes for Us telah berhasil membuat simulasi yang menguatkan aksen kriminal dengan pemilihan wardrobe yang konsisten. Dari awal scene hingga terakhir, warna pakaian yang banyak digunakan ialah warna hitam.

Hitam memiliki makna denotasi warna, yang biasa diaplikasikan dalam banyak hal, salah satunya baju. Makna konotasi hitam ialah kelam, gelap. Citra seorang kriminal dikenal oleh khalayak umum sebagai citra yang gelap, maka simulasi pun dibuat dengan melibatkan warna-warna pakaian dominan gelap di sepanjang film. Simulasi ini tergambar dengan jelas pada tiga tokoh pendukung perempuan, yang digadang-gadang sebagai ahli senjata dan bela diri tingkat tinggi.

Ketiga tokoh pendukung perempuan, yang masing-masing diperankan oleh Dian Sastrowardoyo, Julie Estlle dan Hannah Al Rashid mengenakan setelan biker jacket. Makna denotasi dari biker jacket adalah salah satu jenis jaket berbahan kulit. Dalam lingkup fesyen dunia, biker jacket yang biasanya diproduksi dalam warna gelap memiliki makna lebih dari sekadar penghangat tubuh bagi pengendara motor atau penggemar musik rock.

Sedangkan makna konotasi yang sering tercipta ialah pengguna biker jacket sering diasosiasikan sebagai sosok pemberontak yang mendobrak kemapanan. Biker Jacket memiliki cerita unik dibalik "jiwa pemberontak". Jaket 
ini lahir di abad ke-20, pada era Perang Dunia Kedua, artinya jaket ini telah "mejelajah" waktu yang sangat panjang hingga tetap relevan di jaman sekarang. Awalnya, jaket ini dbuat untuk seragam militer, sama seperti "saudara" beda modelnya yang juga cukup populer hingga saat ini, yaitu bomber jacket. Terbuat dari bahan kulit, biker jacket mengandalkan kualitasnya untuk menghangatkan penggunanya.

Selayaknya bahan kulit asli, biker jacket di awal-awal masa kelahirannya lebih banyak berwarna kulit asli, yaitu cokelat ketimbang hitam. Seiring berkembangnya jaman, para produsen biker jacket pun bermunculan. Lama kelamaan biker jacket menjadi simbol dari pemberontakan dan pergeseran budaya, terutama untuk para muda mudi yang menganggap jaket ini "keren". Beberapa selebriti dunia turut memopulerkan biker jacket, diantaranya ialah Marlon Brando yang kemudian menjadikan jaket ini sebagai salah sati icon dalam fesyen. Selain itu masih ada sumbangan band The Ramones yang melekatkan citra subkultur rock dan punk pada jaket ini.

Realitas para kriminal perempuan yang digambarkan pada film ini adalah realitas cerita yang sebenarnya adalah realitas nyata yang dikodekan demi mendukung simulasi. Objek mempermudah proses klasifikasi sosial, artinya objek atau tanda tertata sebagai nilai yang menentukan status dalam hierarki sosial (Haryatmoko, 2010). Penggunaan warna hitam pada tokoh perempuan dalam film ini semakin juga menguatkan citra perempuan kriminal. Padahal, dalam kehidupan nyata, siapa pun bisa menggunakan biker jacket tanpa harus menjadi kriminal.

Hiperealitas dalam konsep Baudrillard ialah sebuah gejala di mana banyak bertebaran realitas-realitas buatan yang bahkan tampak lebih riil dibandingkan dengan realitas sebenarnya. Dalam kasus film The Night Comes for Us yang bergenre gore atau film-film yang sarat akan adegan pertumpahan darah, aspek bahasa tubuh menjadi penting untuk menghadirkan simulasi hingga menuju hiperalitas. Film ini menghadirkan bela diri khas Indonesia, pencak silat, dalam balutan koreografi pertarungan.

Meskipun begitu, dalam adegan pertarungan antar tokohnya hampir selalu menggunakan bantuan senjata, baik senjata tajam maupun senjata api. Ideologi kekerasan yang dianut pada The Night Comes for Us seolah ingin menunjukkan dalam "pertarungan" kehidupan nyata manusia hanya memiliki dua pilihan, yaitu membunuh atau dibunuh. Dari berberapa cuplikan adegan pertarungan penulis memaknai, fase simulasi berkembang menjadi fase simulakra atau menuju hiperalitas.

Hal ini diperlihatkan dengan adegan-adegan pembunuhan menggunakan senjata tajam hingga memperlihatkan darah. Pemilihan musik latar yang dramatis mendukung fase simulasi menjadi fase simulakra. Akibatnya penonton pun dibuat larut dalam hiperealitas kesadisan yang disajikan secara konsisten dan berulang disepanjang film. Kesuksesan produsen film menjembatani fase representasi hingga menuju hiperealitas dikhawatirkan penulis dapat menjadi umpan balik negatif bagi citra masyarakat Indonesia. 


\section{Simpulan}

Citra dan realitas yang dihadirkan dalam film The Night Comes for Us tidak bebas nilai, sebab Netflix dan sineas pembuatnya memproduksi film dalam sebuah citra terentu untuk menggaet lebih banyak penonton dan pelanggan. Kita tak boleh memandang film yang dibuat secara komersial sebagai sebuah medium yang mewakili kenyataan sosial secara faktual dalam pengertian langsung dan empiris (Heryanto, 2018). Seperti halnya iklan, konsep mengenal Indonesia yang disajikan dalam Netflix original movies dibuat dengan cara mengonstruksikan realitas kehidupan sehari-hari.

Sebagai industri, Netflix original movies juga tidak lepas dari imperatif komersial. Tidak hanya mengenalkan sineas-sineas Indonesia di kancah dunia, ia juga adalah komoditas yang dibuat untuk mendapatkan profit atau keuntungan. Seperti dipercayai Adorno dan Horkheimer (2002), bahwa big business yang mengontrol kandungan pesan media bekerja untuk tujuan ideologis tertentu. Ideologi kekerasan dan kriminalitas yang ditampilkan dalam The Night Comes for Us tidak mewakili realitas Indonesia. Realitas yang diciptakan dalam film ini bukanlah realitas yang sebenarnya terjadi, melainkan hanya sebuah banalitas, kepura-puraan dan kebohongan kosong.

Walaupun penikmat film pada umumnya sadar, bahwa realitas dalam film adalah realitas yang dikonstruksikan, namun bukan tidak mungkin banalitas akan tercipta bagi penonton Netflix dari negara lain yang tidak mengenal latar belakang negara Indonesia atau bahkan belum pernah berkunjung. Sehingga, dikhawatirkan pemahaman tentang negara dan masyarakat Indonesia yang utopis seperti dijabarkan di film The Night Comes for Us dianggap sebagai sebuah realita. Seperti dikatakan Baudrillard, hiperalitas akhirnya menciptakan keadaan ketika sesuatu yang nyata bercampur dengan sesuatu yang abstrak atau keadaan di mana sudah tidak ada lagi perbedaan mana yang nyata dan mana yang abstrak.

Meskipun begitu, jelas fase-fase simulasi yang dilakukan dalam film cenderung meneguhkan ideologi status quo dalam hal ini bertujuan untuk menarik minat sebanyak-banyaknya penonton untuk berlangganan Netflix. Kesimpulan selanjutnya, penulis menilai upaya sineas produser The Nights Comes for Us dengan membentuk citra kriminal Indonesia dalam film ini sebagai upayanya untuk membedakan diri atau menjadikan wacana world class criminal sebagai ciri khasnya dibandingkan film-film bergenre kriminal Indonesia yang lain.

Legitimasi dan integrasi kelas sosial terlihat dalam penggunaan Bahasa Inggris dan Mandarin yang digunakan dalam beberapa scene. Para pelaku kriminal anggota Triad ditampilkan tidak memiliki kapital ekonomi yang mapan, namun memiliki kapital budaya, kapital sosial, dan kapital simbolis yang menjadikan mereka lebih dari sekadar kriminal biasa. Dari kacamata distinction Pierre Bourdieu, penulis menilai ini merupakan strategi untuk membedakan kelas baik dari segi cerita dan penokohan, juga dari sisi film positioning di mata audiens Netflix.

Tulisan ini membuka kesempatan lain untuk dikembangkan dalam penelitian lanjutan, misalnya lebih fokus kepada para penggemar film jenis ini dan pengguna Netflix. Film The Night Comes for Us bisa dikatakan anomali dari 
film Indonesia yang banyak beredar dipasaran. Selain genre yang sangat jarang digunakan, produsen film berupaya secara maksimal menggunakan berbagai teknik film dan editing seperti menjadi sekelas besutan Hollywood.

Apabila kita menganggap film adalah produk kebudayaan yang bisa membantu mempromosikan citra negara, maka sudah saatnya upaya ini didukung penuh oleh pemerintah tanpa mengurangi kreativitas produsennya. Sehingga simulasi dapat diciptakan untuk membantu promosi Indonesia melalui kebudayaan, tanpa menghilangkan jatidiri bangsa.

\section{Ucapan Terima Kasih}

Publikasi penetilian ini terwujud oleh bantuan dari berberapa pihak. Penulis mengucapkan rasa terima kasih yang sebesar-besarnya kepada seluruh pihak yang telah membantu dan mendukung penulis selama proses penelitian berlangsung, hingga diterbitkannya penelitian ini.

\section{REFERENSI}

Adorno, T \& Horkheimer, M. (2002). Dialectic of Enligtenment. California : Stanford University Press

Allen, Graham. 2003. Roland Barthes. London-New York: Routledge

Anholt, Simon. (2007). Competitive Identity: The New Brand Management for Nations, Cities and Regions. New York : Palgrave Macmillan

Barthes, Roland. 1972. Mythologies, terj. Annette Lavers. London : Paladin

Baudrillard, Jean. (1983). Simulations. New York: Semiotext.

Baudrillard, Jean. (1994). Simulacra and Simulations, terj. Sheila Faria Glaser. Michigan : The University of Michigan Press.

Bourdieu, P. (1984). Distinction: A Social Critique of the Judgement of Taste, London: Routledge.

Cresswell, John W. (2009). Research Design : Qualitative, Quantitative, and Mixed Methods Approachs. London : Sage Publication.

Heryanto, Ariel. (2018). Identitas dan Kenikmatan : Politik Budaya Layar Indonesia. Jakarta : KPG.

Haryatmoko. (2010). Dominasi Penuh Muslihat. Jakarta : Gramedia Pustaka Utama.

Kunczik, Michael (1997). Images of nations and international public relations. London: Routledge

Tyron, C. (2015). TV Got Better: Netflix's Original Programming Strategies and Binge Viewing. Media Industries Journal 2.2 (2015), ISSN: 2373-9037, $104-116$

Yulianti, F.D., Bajari, A., Mulyana, S. (2017). Representasi Maskulinitas Dalam Iklan Televisi Pond's Men \#Lelakimasakini. Jurnal Komunikasi, No.10(Vol2). http://dx.doi.org/10.24912/jk.v10i2 